\title{
Sociodemographic and clinical profile of patients with occupational contact dermatitis seen at a work-related dermatology service, $2000-2014^{*}$
}

\author{
Maria das Graças Mota Melo ${ }^{1}$, Ana Luiza Castro Fernandes Villarinhoํㅜ, Iuri da Costa Leite ${ }^{2}$
}

DOI: http:/ / dx.doi.org/10.1590/abd1806-4841.20197235

\begin{abstract}
BACKGROUND: Occupational dermatoses are common, especially contact dermatitis. Epidemiological studies on these dermatoses are scarce in Brazil and they are necessary as part of the public policy to protect workers' health.

Oвjестіves: To identify sociodemographic and clinical profile of patients with occupational contact dermatitis seen between 2000 and 2014 at an occupational dermatology service.

MetHODs: It is a cross-sectional and retrospective study, based on information obtained from the service's database.

RESULTS: Of 560 patients with conclusive patch test, 289 (46.9\%) presented occupational dermatoses and 213 occupational contact dermatitis with predominance of the allergic type in relation to the irritative type (149:64 respectively). The odds of occupational dermatoses were higher among men and lower among patients aged 50 years or older and with higher level of education. Regarding the possibility of presenting occupational allergic contact dermatitis, only the gender variable was statistically significant. The professions most seen were cleaners, construction workers, painters, mechanics/metallurgists and cooks. The commonest allergens were nickel sulfate, potassium dichromate, cobalt chloride, carba-mix and formaldehyde. STUDY LIMITATIONS: The main limitations of this study are the fact that it was carried out in a tertiary service of occupational dermatoses and the lack of access to some allergens outside the patch test baseline series.

Conclusions: It was possible to identify the sociodemographic and clinical profile of patients with suspected occupational contact dermatitis seen at the Service, beyond the professional groups and allergens related to a high risk of occupational contact dermatitis in this population.
\end{abstract}

Keywords: Chemical compound exposure; Dermatitis, contact; Dermatitis, occupational; Occupational health

\section{INTRODUCTION}

Occupational dermatosis (OD) are frequent and the available statistics usually underestimate the incidence and prevalence of these conditions. In this sense, Brazil is no exception because despite the notification being compulsory, cases are under-notified. Be- sides, epidemiological studies in this area are lacking in the country and the indexes of underdiagnoses are quite high. ${ }^{1}$

The indexes of OD reported in the literature are variable. Lower indexes are seen in countries were industrial automation and

Received 19 May 2017.

Accepted 30 November 2017.

* Work conducted at Service of Work-Related Dermatology, Centro de Estudos da Saúde do Trabalhador e Ecologia Humana, Escola Nacional de Saúde Pública Sergio Arouca, Fundação Oswaldo Cruz, Rio de Janeiro (RJ), Brazil.

Financial support: None.

Conflict of interest: None.

1 Sector of Occupational Dermatology, Centro de Estudos da Saúde do Trabalhador e Ecologia Humana, Escola Nacional de Saúde Pública Sergio Arouca, Fundação Oswaldo Cruz, Rio de Janeiro (RJ), Brazil.

2 Department of Epidemiology and Health Quantitative Methods, Escola Nacional de Saúde Pública Sergio Arouca, Fundação Oswaldo Cruz, Rio de Janeiro (RJ), Brazil.

MAILING AdDRess:

Maria das Graças Mota Melo

E-mail: grmotamelo@gmail.com

C2019 by Anais Brasileiros de Dermatologia 
the employment of new technologies in industries were adopted. These measures cause reduction of the direct exposure of the total amount of workers to irritant and allergenic products. ${ }^{2}$

There is consensus regarding the presence of under-notification of the cases of occupational cutaneous diseases due to the absence of detection/diagnosis or medical access. ${ }^{3}$ The frequencies of OD reports vary between countries according to the definition of a case, data collection methods, reporting system and variability of the level of industrialization. ${ }^{4}$ Even in developed countries like Germany, it was estimated that the number of unreported cases of occupational cutaneous disease could be 50 to 100 times higher than those notified. ${ }^{5}$

Contact dermatitis (CD) is of special interest among OD due to the frequency in which it occurs, occupying the first place. It is triggered by chemical products in contact with the skin that, in turn, have the potential of causing an irritant or allergic cutaneous reaction. Traditionally, irritant contact dermatitis (ICD) has been considered the most frequent. However, in some studies, allergic contact

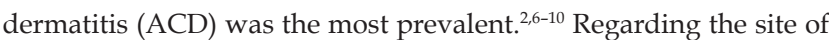
the lesions, hands are the most commonly affected areas. Other sites can be involved, depending on the exposure method and the intensity of the allergic reaction.

Keegel et al, when conducting a systemic review of the epidemiology of occupational contact dermatitis (OCD), noticed the scarcity of reports in the literature on the incidence and prevalence of these dermatoses and, therefore, the information available might not reflect the reality. They refer to records of spontaneous or compulsory reports based in clinics, hospital and population base. ${ }^{4}$

There are few studies in Brazil that address the epidemiological aspects, the sociodemographic and clinical profile of patients, as well as the impact of these dermatoses in the society and individuals due to absenteeism, job loss and impairment in the quality of life. Therefore, researches that contribute to broaden this knowledge will be extremely helpful, besides contributing to the implementation of prevention policies of OD in workers' health programs.

The objective of this study was to identify the sociodemographic and clinical profile of patients with occupational contact dermatitis seen from 2000 to 2014 in a tertiary service of work-related dermatoses.

\section{METHODS}

This is a descriptive, cross-sectional and retrospective study based on the processing of secondary information from the database of a service of work-related dermatology at the Centro de Saúde do Trabalhador e Ecologia Humana da ENSP/FIOCRUZ, that acts in a tertiary level and is reference in workers' health. Data are documented electronically at the service of Dermatology with Epi-Info version 3.5.2.

The project was approved by the ethics committee of the institution where it was performed (document number: 59944016400005240).

The majority of the patients come from the public service, referred by professionals of the Sistema Único de Saúde (SUS) or from the institution of the service. The patients fill out a questionnaire with information on sociodemographic characteristics, main complaint, history of the current illness, associated complaints, personal and family history, including information regarding allergy, and previous treatments.

The patients with clinical manifestations suggestive of contact dermatitis and older than 18 years of age were submitted to patch testing. All were tested with the Brazilian Standard Series, made by 30 substances, identified in a multicentric study performed by the Grupo Brasileiro de Estudo de Dermatite de Contato (GBEDC) as the most frequent causes of allergy in Brazil. ${ }^{11}$ The application technique was according to standards defined by the GBEDC. The substances were applied to the back, with Finn Chambers-like patches (EpitestLtd, Oy, Finland). Readings were conducted at $48 \mathrm{~h}$ and $96 \mathrm{~h}$ after the application of the test or more, if necessary. The reading criteria adopted were those established by the International Contact Dermatitis Research Group (ICDRG). Tests with reactions classified as,+++ or +++ were considered positive. Additional tests were applied as needed. The patient with relevant positive tests received a medical report indicating the diagnosis, the substances to which they were sensitized and the protection measures that should be put in place.

The beginning of the study corresponded to the time when the methodology of the test with the Brazilian Standard Series started being used in the service. Patients with no suspected contact dermatitis in the first assessment were excluded, as well as those who did not complete the test or who were lost to follow-up.

The concept of work-related dermatosis in this study was established by the Ministry of Health: "all change in mucous membranes, skin and annexes that is directly or indirectly caused by, conditioned to, maintained by or exacerbated by agents present in occupational activity or in the work place". ${ }^{12}$

The criteria used for the diagnosis of ACD were the clinical appearance of the dermatosis, its location, course, history of contact with substances considered capable of triggering allergic cutaneous reactions, positive contact tests and their clinical relevance. For the diagnosis of ICD, besides the clinical aspects and course, we considered the exposure to products capable of causing cutaneous irritation and negative contact test.

Were considered as conclusive for OCD the cases where it was possible to establish a connection between the contact dermatitis and the occupational activity. The cases in which the patch test was positive and relevant were classified as occupation allergic contact dermatitis (OACD). When the test was negative or positive without relevance but there was exposure to substances known to be skin irritants, it was recorded as occupational irritant contact dermatitis (OICD). Non-occupational cases were considered as those in which it was possible to exclude a connection to the occupation; inconclusive were those in which it was not possible to confirm or exclude the connection, in many cases due to interruption of the investigation. Those cases were excluded from data analysis.

The variables analyzed were: sex; age (age group); race/ skin color (Caucasian, brown, dark-skinned); personal atopic history (yes, no); schooling (incomplete primary school, complete primary school, incomplete secondary school, complete secondary school, university degree or above); occupational activity (cleaners, construction workers/janitor, painters, mechanic/metallurgist, 
cooker and others); allergens in the Brazilian Standard Series and some additional tests.

The ratio of patients by sex, age group, schooling, personal atopy, race/color was calculated. We considered atopy the history of allergy to airborne allergens and/or clinical manifestations of eczema, rhinitis or asthma. The mean age and standard deviation for the population with occupational dermatosis, occupational contact dermatitis and also sex in those two groups was calculated. The association between these variables and the occurrence of occupational dermatosis was made using a logistic model. Only statistically significant variables at the $25 \%$ level $(\mathrm{p}<0.25)$ obtained from the non-adjusted models were maintained in the adjusted model. ${ }^{13}$

Among patients with occupational contact dermatoses (ODs), the occupations were listed by decreasing order of frequency for the total population and divided by sex.

The patch test results were classified according to the three commonest occupations, by sex and relevance of the test.

The sites of the lesions of the three more frequently seen occupations were related to sex.

OCD patients (irritant and allergic) were classified according to sociodemographic and clinical characteristics. The association between these variables and the chance of the patients having allergic or irritant contact dermatitis was obtained through a logistic regression model. Statistically significant variables at the $25 \%$ levels obtained in the non-adjusted models were maintained in the adjusted model. ${ }^{13}$ The number of patients diagnosed with OACD, OICD or both, according to sex and occupation was also calculated.

All analyses were performed with the Statistical Analysis System software version 9.3. ${ }^{14}$

\section{RESULTS}

In the OD, from 2000 to 2014, a total of 616 patients with a dermatological condition consistent with contact dermatitis underwent investigation with patch testing. However, for purposes of data analysis, all inconclusive cases (56) were excluded, with a new total of 560 patients. We observed the majority 337 (60.2\%) was female. Two hundred and eight-nine (46.9\%) cases were conclusive for occupational dermatosis (OD) and 271 (44\%) for non-occupational dermatosis (NOD). Mean patient age with occupational dermatosis was 42.9 years $( \pm 10.8)$, with 44.6 years $( \pm 11.1)$ for men and 41.2 years $( \pm 10.3)$ for women. Among the work-related cases, there were $213(73.7 \%)$ cases of occupational contact dermatitis with the predominance of the allergic type over the irritant (149:64, respectively).

The occurrence of occupational dermatosis according to the sociodemographic and clinical variables of the patients selected for the research (560 cases) is shown in table 1 . As can be seen, the only variable that did not show association with the odds of developing occupational dermatosis in the non-adjusted model was personal history of atopy. The odds of developing occupational dermatosis was lower among atopic patients, although without statistical significance. After the application of the adjusted model, we also observed a loss of the statistical significance for the association with race/color. Men were more prone to developing occupational dermatosis (OR=1.74; 95\% CI: 1.15-2.62). Regarding age, we observed lower odds only among patients aged 50 years or older when compared to those between 40 and 49 years (OR=0.49; 95\% CI: 0.30-0.81).

Considering schooling, the chance of the patient having OD was $52 \%(\mathrm{OR}=0.48$; 95\% CI: $0.29-0.82)$ and $78 \%$ (OR=0.22; 95\% CI: 0.11-0.45) lower among individuals with complete secondary school or that had undertaken any university course when compared to those with incomplete primary school, respectively.

The prevalent occupations among occupational cases are shown in figure 1 . The groups with higher number of patients were those with activities related to cleaning (89/30.8\%), construction worker/janitor $(46 / 15.9 \%)$, painter $(16 / 5.5 \%)$, mechanic/metallurgist (14/4.8\%), cooking (13/4.5\%), houseworkers (11/3.8\%) and health professional $(10 / 3.5 \%)$. The remaining occupations were grouped as "others" and comprised 90 (31.1\%) individuals.

The prevalent occupations for men with OD were: construction worker/janitor $(46 / 32.6 \%)$, painter $(16 / 11.3 \%)$, cleaner (16/11.3\%), mechanic/metallurgist (14/9.9\%) and woodworker/ carpenter $(7 / 5 \%)$. The most common occupations among women were: cleaner $(73 / 49.3 \%)$, houseworker $(11 / 7.4 \%)$, health professional $(9 / 6.1 \%)$, cook $(8 / 5.4 \%)$ and seamstress $(7 / 4.7 \%)$ (Figure 2$)$.

The five most common contact allergens with occupational connection in this study were: nickel sulfate $(84 / 56.4 \%)$, potassium dichromate $(71 / 47.6 \%)$, cobalt chloride $(52 / 34.9 \%)$, carba-mix $(27 / 18.1 \%)$ and formaldehyde $(25 / 16.8 \%)$.

Patch test positivity by the three most commonly seen occupations at the service, according to sex and test relevance are shown in table 2.

Construction worker/janitor rated first among male activities. Potassium dichromate was positive in 35 (76.1\%) of the 46 construction workers with occupational dermatosis. Cobalt chloride was the second most prevalent allergen with 17 (36.9\%) cases. Rubber additives carba-mix and thiuram-mix stood out with 11 (23.9\%) and $6(13 \%)$ cases, respectively. Neomycin allergy occurred in 7 cases $(15.2 \%)$.

The second prevalent occupation was painter and the most commonly involved allergen was epoxy resin (6/37.5\%). Occupations related to cleaning participated with 16 cases, with no specific distinct allergen. Those prevalent were kathon CG (3/18.75\%) and formaldehyde $(3 / 18.75 \%)$ which can be present in cleaning products.

Regarding the 73 women who were cleaners, we observed that $25(34.2 \%)$ had allergy to nickel sulfate but in almost $50 \%$ it was not relevant to the occupational dermatosis. No one allergen stood out with the 2 other most prevalent occupations (houseworkers and health professionals).

The sites of the lesions with the three occupations most frequently seen were also analyzed according to the sex (Table 3).

In this study, the involvement of the hands was seen in 203 patients $(70.2 \%)$. Regarding the three occupations most commonly seen, we observed that hands, forearms, arms and wrists were the most affected areas, regardless of the sex. For the activity construction worker/janitor, we observed multiple body sites involved. The involvement of the dorsum of the hands occurred in $65.8 \%$ of patients who were cleaners.

OCD cases corresponded to $79.2 \%$ of the 289 work-relat- 
Table 1: Odds ratio of occupational dermatosis, confidence interval and p-values, according to sociodemographic and clinical characteristics

\begin{tabular}{|c|c|c|c|c|c|c|c|c|c|}
\hline \multirow[b]{2}{*}{ Characteristics } & \multirow{2}{*}{$\begin{array}{c}\begin{array}{c}\text { To- } \\
\text { tal }\end{array} \\
\mathbf{N} \\
\end{array}$} & \multirow{2}{*}{$\begin{array}{c}\text { OD } \\
\mathbf{N}(\%) \\
\end{array}$} & \multirow{2}{*}{$\begin{array}{c}\text { NOD } \\
\text { N (\%) }\end{array}$} & \multicolumn{3}{|c|}{ Non-adjusted model } & \multicolumn{3}{|c|}{ Adjusted model } \\
\hline & & & & OR & $95 \%$ CI & $p$-value & OR & $95 \%$ CI & $p$-value \\
\hline \multicolumn{10}{|l|}{ Sex } \\
\hline Male & 223 & $141(63.2)$ & $82(36.8)$ & 2.20 & $1.55-3.11$ & $<0.001$ & 1.74 & $1.15-2.62$ & $<0.01$ \\
\hline Female & 337 & $148(43.9)$ & $189(56.1)$ & 1.00 & - & - & 1.00 & - & - \\
\hline \multicolumn{10}{|l|}{ Age } \\
\hline 18 to 29 & 81 & $34(42.0)$ & $47(58.0)$ & 0.51 & $0.30-0.87$ & 0.01 & 0.88 & $0.44-1.73$ & 0.71 \\
\hline 30 to 39 & 123 & $71(57.7)$ & $52(42.3)$ & 0.96 & $0.60-1.53$ & 0.86 & 1.15 & $0.65-2.04$ & 0.63 \\
\hline 40 to 49 & 177 & $104(58.8)$ & $73(41.2)$ & 1.00 & - & - & 1.00 & - & - \\
\hline 50 or older & 179 & $80(44.7)$ & $99(55.3)$ & 0.57 & $0.37-0.86$ & 0.01 & 0.49 & $0.30-0.81$ & $<0.01$ \\
\hline \multicolumn{10}{|l|}{ Schooling } \\
\hline Incomplete primary & 164 & $104(63.4)$ & $60(36.6)$ & 1.00 & - & - & 1.00 & - & - \\
\hline Complete primary & 79 & $41(51.9)$ & $38(48.1)$ & 0.62 & $0.36-1.07$ & 0.09 & 0.71 & $0.40-1.27$ & 0.25 \\
\hline $\begin{array}{l}\text { Incomplete } \\
\text { secondary }\end{array}$ & 42 & $33(78.6)$ & $9(21.4)$ & 2.12 & $0.95-4.72$ & 0.07 & 2.14 & $0.90-5.12$ & 0.08 \\
\hline Complete secondary & 124 & $58(46.8)$ & $66(53.2)$ & 0.74 & $0.51-0.32$ & $<0.01$ & 0.48 & $0.29-0.82$ & $<0.01$ \\
\hline University degree or above & 66 & $17(25.8)$ & $49(74.2)$ & 0.20 & $0.11-0.39$ & $<0.001$ & 0.22 & $0.11-0.45$ & $<0.001$ \\
\hline \multicolumn{10}{|l|}{ Race/color } \\
\hline Caucasian & 197 & $91(46.2)$ & $106(53.8)$ & 1.00 & - & - & 1.00 & - & - \\
\hline Brown & 165 & $100(60.6)$ & $65(39.4)$ & 1.79 & $1.18-2.73$ & $<0.01$ & 1.41 & $0.88-2.26$ & 0.15 \\
\hline Dark-skinned & 111 & $63(56.8)$ & $48(43.2)$ & 1.53 & $0.96-2.44$ & 0.08 & 1.30 & $0.78-2.19$ & 0.31 \\
\hline \multicolumn{10}{|l|}{ Personal atopy } \\
\hline Yes & 224 & $110(49.1)$ & $114(50.9)$ & 0.60 & $0.78-1.19$ & 0.33 & - & - & - \\
\hline No & 309 & $165(53.4)$ & $144(46.6)$ & 1.00 & - & - & - & - & - \\
\hline
\end{tabular}

Source: Developed based on the information from the database of patients seen at the service of work-related dermatology, 2000-2014. OD: Occupational dermatosis; NOD: Non-occupational dermatosis; OR: Odds ratio; CI: Confidence interval

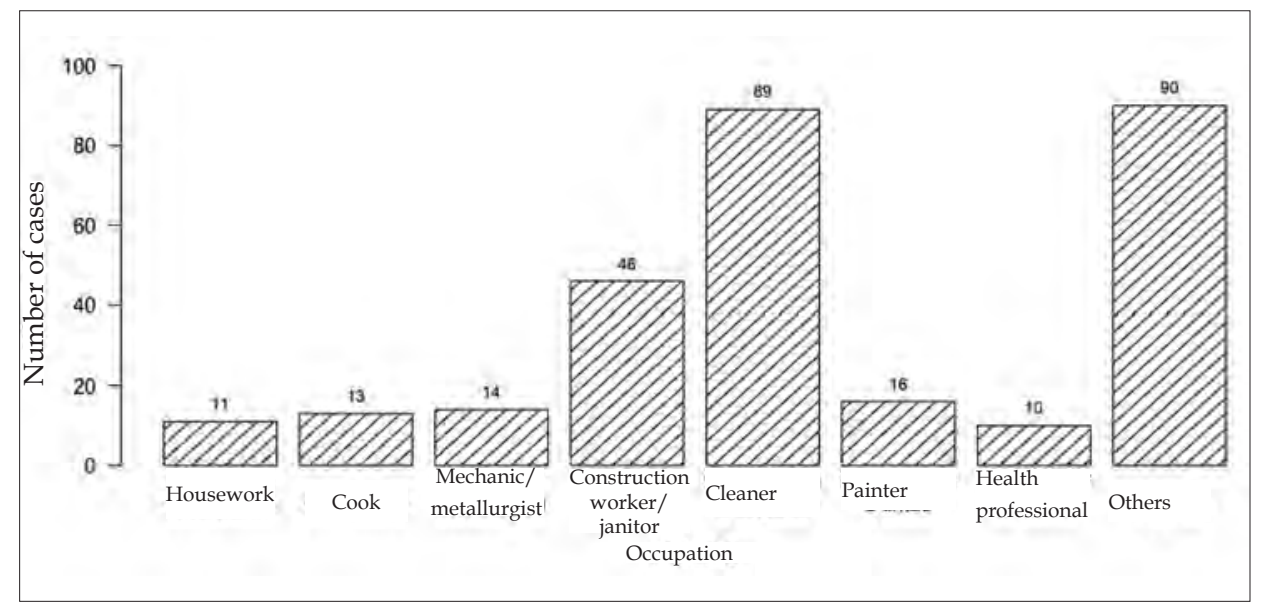

Figure 1: Number of patients classified as having occupational dermatosis, according to occupation Source: Developed based on the information from the database of patients seen at the service of work-related dermatology, 2000-2014. ed cases. OACD was predominant among those patients (65.1\%); in 16 cases $(7 \%)$, we observed an association of OACD and OICD. The diagnosis of occupational dermatosis non-contact dermatitis was made in $60(20.8 \%)$ individuals. These cases were distributed as: unspecified contact dermatitis/inconclusive: 12 (20\%); contact and induced urticaria: 9 (15\%); tinea manuum 7 (11.6\%); tinea pedis:
7 (11.6\%); psoriasis: 5 (8.3\%); chronic paronychia: 5 (8.3\%); chemical leukoderma: 3 (5\%); atopic dermatitis: $2(3.3 \%)$ and the remaining 10 $(16.6 \%)$ cases occurred only once.

Table 4 shows the distribution of OCD patients according to the type of dermatitis (irritant and allergic), sociodemographic and clinical characteristics. Regarding the non-adjusted model, 


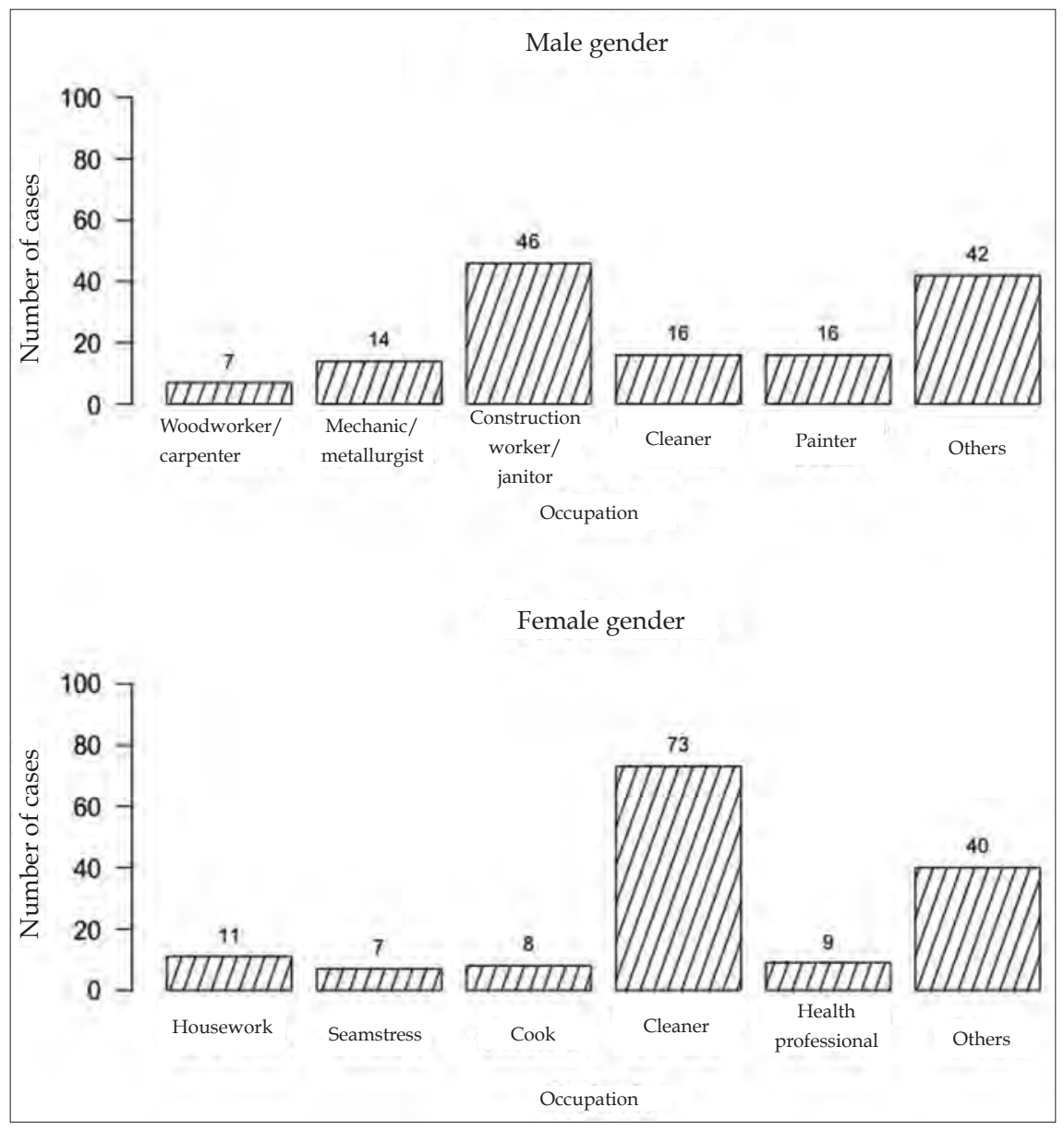

FIGURE 2: Number of patients classified as having occupational dermatosis, according to sex and occupation

Source: Developed based on the information from the database of patients seen at the service of work-related dermatology, 2000-2014. the chance of developing OACD was higher among male patients (OR=5.76; 95\% CI: 2.92-11.36) and brown (OR=2.28; 95\% CI: 1.10$4.74)$ and lower among atopic patients (OR=0.39; 95\% CI: 0.21-0.73). However, the variable atopy lost statistical significance in the adjusted model.

The odds of OACD among men was approximately five times higher $(\mathrm{OR}=6.15 ; 95 \% \mathrm{CI}: 2.82-13.41)$ than that seen among women. Of note, the odds were also higher among brown patients $(\mathrm{OR}=2.02 ; 95 \% \mathrm{CI}: 0.91-4.52)$, although the statistical significance was borderline $(\mathrm{p}=0.08)$.

In the occupation analysis, we observed that OACD stood out in the activity construction worker/janitor among men and cleaner among women. For this occupation, the ratio of OICD was superior to OACD and the association between OACD and OICD was more representative in comparison to other activities (Figure 3).

Regarding personal protective equipment (PPE), gloves stood out as a work-related problem with $71(24.6 \%)$ cases. Of those, $30(42.2 \%)$ were considered irritant and $41(57.7 \%)$ allergic.

\section{DISCUSSION}

The frequency of occupational cases among patients submitted to patch testing was close to that of non-occupational cases (51.6\% and $48.4 \%$, respectively). A higher percentage of occupation- al was expected since it is a specialized service for worker's health. This proximity of proportions was also reported by Kanerva et al, who found a percentage of $56.4 \%$ of non-occupational cases referred to the Division of Dermatology of the Occupational Health Institute of Helsinki. ${ }^{15}$ This might represent the difficulty of the non-specialist health professional in identifying occupational cases. The differentiation between conditions with eczematous changes on the hands presents higher difficulty since other dermatoses can present these changes, besides the fact that a contact dermatitis even on the hands does not necessarily mean that it is occupational in origin.

Among OD patients, there was a higher prevalence of males, with a marked gender division of labor in occupations that require more physical effort. Men were exclusively found in the occupations construction worker/janitor, painters and plumber. Women were exclusively found in housework and seamstress, manicurist and elder care. For cleaners, there was a predominance of females (73:16), what can be explained by the fact that it is an activity traditionally performed by women.

In the present study, the age mean was of 42.9 years $( \pm 10.8)$ among occupational dermatosis cases, supporting the knowledge that the potentially active age group is that most affected by OD. According to the Instituto Brasileiro de Geografia e Estatística (IBGE), the potentially active age group includes persons between 15 to 64 
Table 2: Patch test positivity according to the three most frequently seen occupations by sex and test relevance

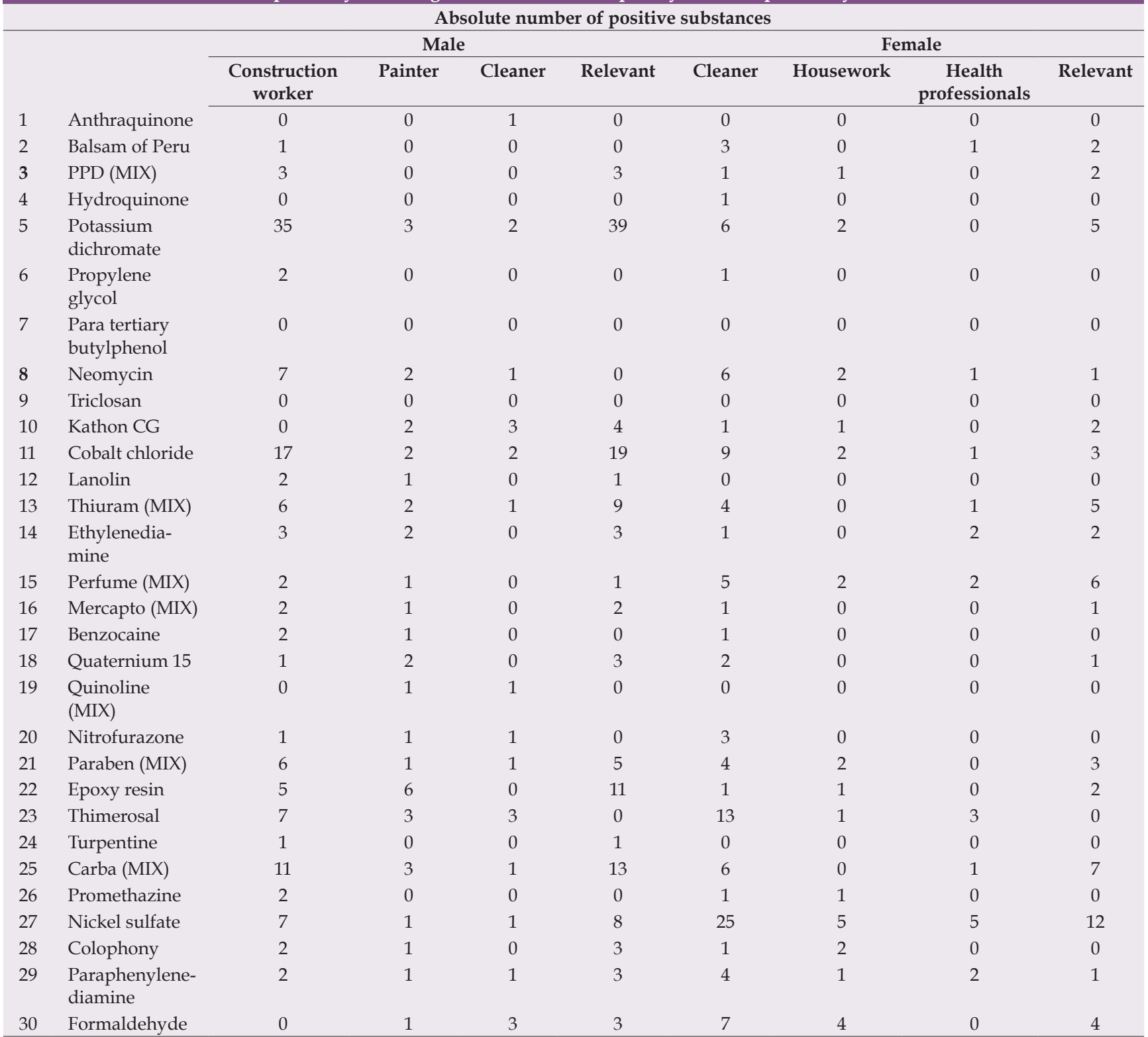

Source: Developed based on the information from the database of patients seen at the service of work-related dermatology, 2000-2014

\section{Table 3: Sites of the lesions of the three most frequently seen occupations}

\begin{tabular}{|c|c|c|c|c|c|c|}
\hline \multirow[b]{2}{*}{ Area of the lesion } & \multicolumn{6}{|c|}{ Women } \\
\hline & $\begin{array}{c}\text { Construction worker/janitor } \\
\mathrm{N}(\%)\end{array}$ & $\begin{array}{l}\text { Painter } \\
\mathrm{N}(\%)\end{array}$ & $\begin{array}{l}\text { Cleaner } \\
\mathrm{N}(\%)\end{array}$ & $\begin{array}{l}\text { Cleaner } \\
\mathrm{N}(\%)\end{array}$ & $\begin{array}{c}\text { Housework } \\
\mathrm{N}(\%)\end{array}$ & $\begin{array}{c}\text { Health professional } \\
\qquad(\%)\end{array}$ \\
\hline Dorsum of the hand & $28(67.9)$ & $7(43.8)$ & $9(56.2)$ & $48(65.8)$ & $7(63.6)$ & $5(55.6)$ \\
\hline Palms & $27(58.7)$ & $6(37.5)$ & $1(6.2)$ & $23(31.5)$ & $8 \quad(72.7)$ & $6(66.7)$ \\
\hline Back & $9(19.6)$ & $4(25.0)$ & $2(12.5)$ & $2(2.7)$ & $2(18.2)$ & $0 \quad(0.0)$ \\
\hline Abdomen & $11(23.9)$ & $1(6.2)$ & $2(12.5)$ & $2(2.7)$ & $1(9.1)$ & $0 \quad(0.0)$ \\
\hline Forearm & $31(67.4)$ & $11(68.8)$ & $8(50.0)$ & $35(48.0)$ & 7 (63.6) & $2(0.0)$ \\
\hline Face and neck & $9(19.6)$ & $8(50.0)$ & $3(18.8)$ & $11(15.1)$ & $3(27.3)$ & $\begin{array}{ll}0 & (0.0)\end{array}$ \\
\hline Legs and thighs & $23(50.0)$ & $7(43.8)$ & $4(25.0)$ & $8(11.0)$ & $1(9.1)$ & $\begin{array}{ll}0 & (0.0)\end{array}$ \\
\hline Dorsum of foot & $12(26.1)$ & $3(18.8)$ & $4(25.0)$ & $8(11.0)$ & $2(19.2)$ & $0 \quad(0.0)$ \\
\hline Soles & $12(26.1)$ & $3(18.8)$ & $3(18.8)$ & $9(12.3)$ & $0(0.0)$ & $0 \quad(0.0)$ \\
\hline Chest & $6(13.0)$ & $2(12.5)$ & $1(6.2)$ & $5(6.8)$ & $1(9.1)$ & $0 \quad(0.0)$ \\
\hline Total & $46(100.0)$ & $16(100.0)$ & $16(100.0)$ & $73(100.0)$ & $11(100.0)$ & $9(100.0)$ \\
\hline
\end{tabular}

Source: Developed based on the information from the database of patients seen at the service of work-related dermatology, 2000-2014 
Table 4: Odds ratio associated to the occurrence of allergic contact dermatitis, confidence intervals and p-values according to sociodemographic and clinical characteristics of patients with occupational contact dermatitis

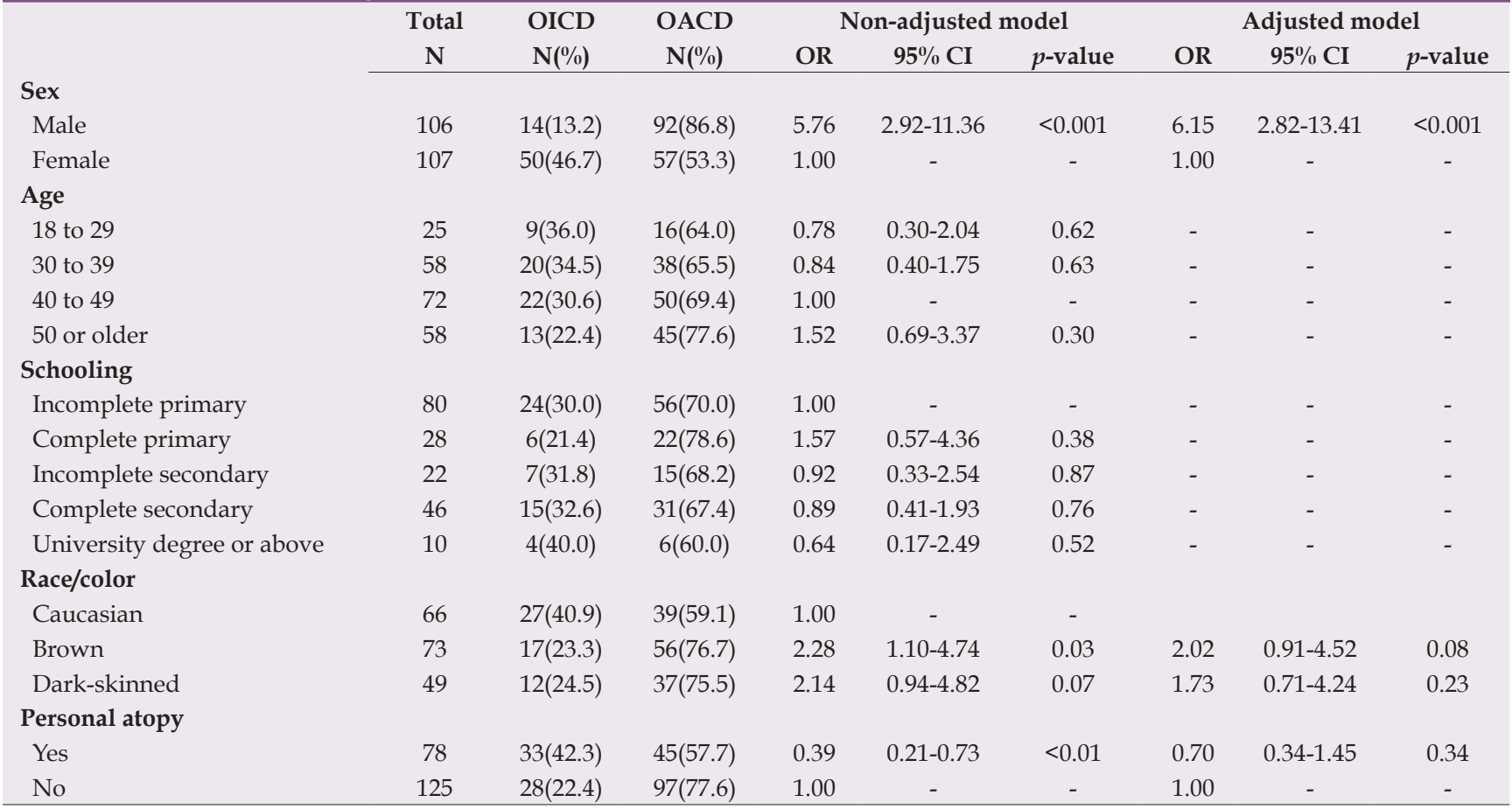

Source: Developed based on the information from the database of patients seen at the service of work-related dermatology, 2000-2014.

Footnote: OICD: Occupational irritant contact dermatitis; OACD: Occupational allergic contact dermatitis; OR: Odds ratio; CI: Confidence interval.

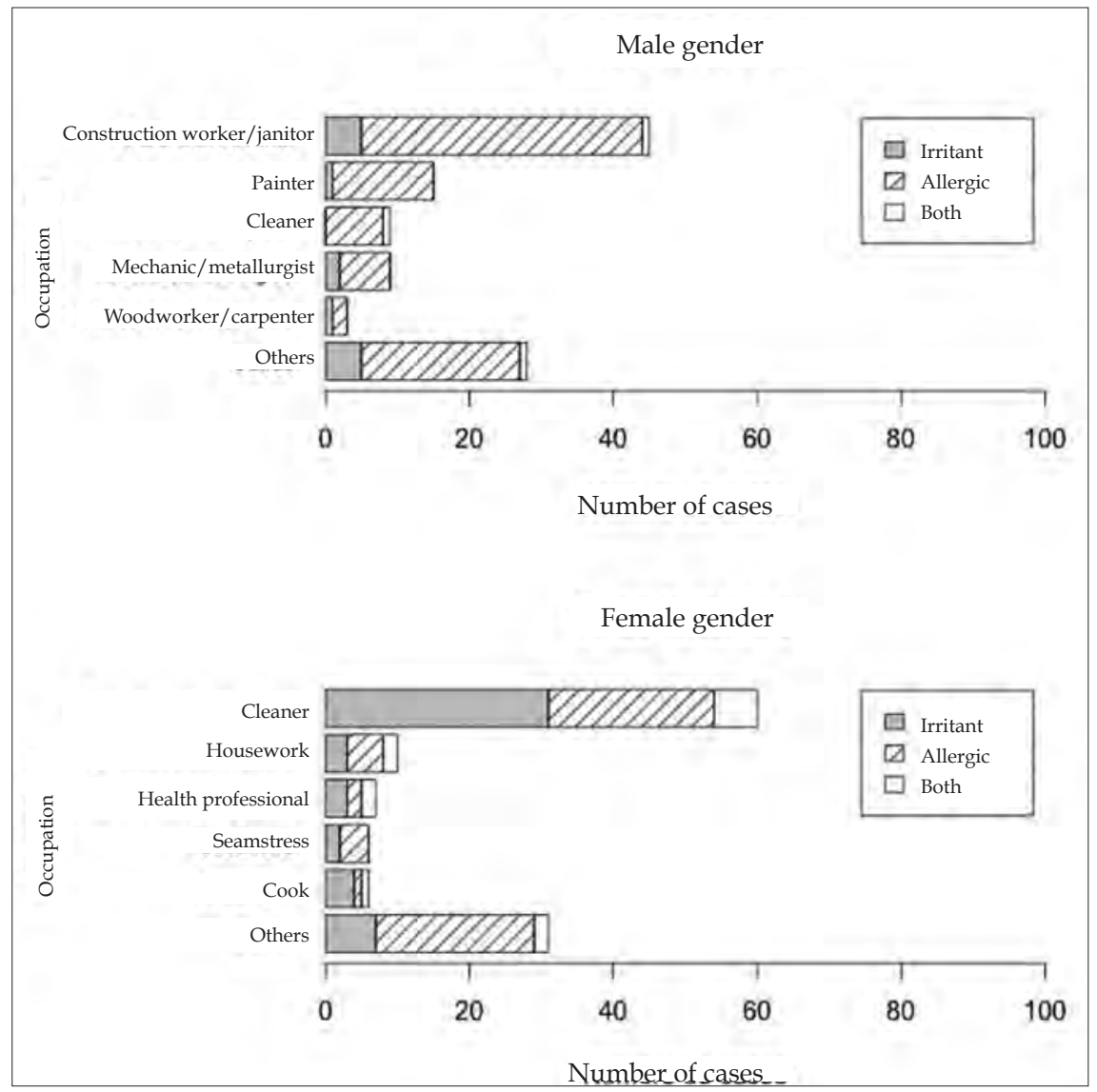

Figure 3: Number of patients diagnosed with occupation allergic contact dermatitis (OACD), occupational irritant contact dermatitis (OICD) or both, by sex and occupation. Source: Developed based on the information from the database of patients seen at the service of work-related dermatology, 2000-2014. 
years of age ${ }^{16}$ The occupational cases are expected to be in this age group. Bhatia et al, when evaluating 117 OCD cases in India, found a mean age of onset of the dermatosis of 40.3 years $( \pm 13.3) .{ }^{10}$ On the other hand, in Germany, a tendency towards younger age groups being affected by occupational cutaneous diseases was observed, with a mean age of 22 years for females and 31 for males. ${ }^{5}$

The predominance of poorer schooling is related to the occupations most seen in the service, such as, for example, construction worker/janitor, cleaners, painters, that are occupations with lower requirements of qualification.

Overall in this study, the evaluation of occupational cases did not show any association between personal history of atopy and occupational dermatosis, either OACD or OICD. However, according to Diepgen, atopic dermatitis is the main cofactor for occupational cutaneous disease, being responsible for approximately $40 \%$ of cases. ${ }^{5}$ Although allergic contact dermatitis is probably less common in atopic individuals, a higher frequency of sensitization to multiple allergens was seen in severe atopic dermatitis patients. ${ }^{17}$ Hand irritant contact dermatitis is prevalent in atopic individuals. ${ }^{18}$

In this study, most patients with occupational dermatosis were brown or dark-skinned. This can be explained by the profile of the occupations most seen at the service which, in Brazil, due to social historic aspects, are more commonly performed by brown and dark-skinned individuals. The loss of statistical significance of the association race/color with occupational dermatitis can be explained by the fact that most patients seen at the service, in particular males, have higher phototypes. It must be considered that in the adjusted model, the only variable that was indicated as a strong predictor of OCD was male gender.

It is expected that an occupational dermatosis will commonly affect the hands, which are human's working main tools. Other areas and even the whole body can be affected, depending on the route of exposure and severity of the allergic reaction. In this study, hands were the most commonly affected area with 203 cases (70.2\%). For the occupation of construction worker/janitor, we observed the involvement of various areas of the body what in reality can correspond to the route of exposure (air dispersion) and/or the dissemination of the dermatitis. The involvement of the dorsum of the hands occurred in $65.8 \%$ of cleaners, probably related to allergy or irritation to rubber gloves used as PPEs. Only 16 men with occupational dermatosis were cleaners and also showed a predominance of involvement of the dorsum of the hands over the palms (9:1). Of those, 5 presented with glove CD. For houseworkers and health professionals, there was a balance between the involvement of dorsum of the hands and palms, indicating a higher prevalence of allergy or irritation by chemical products and foods.

Boonchai et al. found a percentage of $51.5 \%$ of hand involvement. ${ }^{9}$ Bhatia et al. demonstrated in their study that, leg involvement was more frequent than in studies conducted in the West. ${ }^{10}$ This was attributed to the habits of New Delhi's workers, who do not cover their legs due to the high temperatures in the workplace. This datum highlights the importance of the route of exposure to the allergen in the location of lesions.

In this study, OACD was more prevalent than OICD, with $149(57.3 \%)$ and $64(21.8 \%)$ cases, respectively. We believe the con- tributing factor for this datum was the fact that the service is specialized in OD and receives hard-to-diagnose and hard-to-control allergy cases, and the fact that irritant cases have already become allergic. This aspect is well depicted by construction workers, who initially present with cement OICD that progresses to cement allergy. In a Danish study by Caroe et al. in 2010, 70\% of 1,504 validated cases were found to be OICD. ${ }^{19}$ In Chile, the rate of ICD was $60 \%$ and ACD, 31\%. ${ }^{7}$ In contrast, Kucenic et al. ${ }^{8}$ found OACD more frequently $(60 \%)$ than OICD (34\%). Boonchai et al, in Thailand, reported ACD in $76.3 \%$ of cases. ${ }^{9}$ Bhatia et al. also found OACD in $57 \%$ of OCD patients. ${ }^{10}$

Regarding the evaluation of occupational cases according to the occupations, the variations are a consequence of the population studied: if agricultural, industrial, outsourced type, type of technology used, investments in worker's health. This makes comparison between studies difficult and should be taken into consideration in the analysis of epidemiological studies. Boonchai et al. consider that differences in the workplace, exposure to chemical substances and weather can influence the epidemiological indicators of OCD. ${ }^{9}$

In this study, the occupations most commonly seen are in accordance to the national publications cited in this article: cleaners, construction worker/janitor, painter, mechanic/metallurgist and cook. All these services can be considered as outsourced type and most workers are covered by labor laws (Consolidação das Leis Trabalhistas - CLT), and therefore have a higher chance of being identified due to social security and labor rights ensured by this work contract. Another fact to be considered is the location of the study in a city where there is predominance of outsourced activities. Brazil has continental dimensions with significant economical and industrial variations among the States, generating differentiated work activities that should be considered in epidemiological evaluations. Besides, prevalent occupations among men and women are not all the same, leading to the exposure of different chemical products between the genders, according to the type of work.

A nation-wide data collection in the United States on the incidence of OCD from 1973 to 1991 showed that the populations under higher risk were those in agriculture, forestry and fishing, with an incidence of 0.3 case per 1,000 persons, while those working in industries had an incidence of 0.2 case per 1,000 persons. ${ }^{20}$ Bhatia et al, in a study in India, found OD most frequently in farmers, followed by construction workers and housewives. ${ }^{10}$

In Brazil, Duarte et al, when studying the frequency of OCD in an dermatologic allergy outpatient clinic in São Paulo, found cases of OCD more frequently in cleaners, construction workers and mechanics/metallurgists. ${ }^{21}$ GBEDC found similar results when conducting the multicentric study to establish a standard Brazilian series for patch testing. ${ }^{11}$ Reis et al. evaluated the clinical-occupational profile of 180 patients seen with suspected OCD in an Occupational Medicine outpatient clinic in Campinas (São Paulo), finding the following occupational groups more frequently: cleaners, construction workers and mechanic/metallurgist. ${ }^{22}$

In the present study, the five most frequently detected contact allergens with occupational relevance were: nickel sulfate, potassium dichromate, cobalt chloride, carba-mix and formaldehyde. Nickel sulfate is the most common sensitizing agent in the world. 
An important aspect is its frequent use in metal objects such as jewelry among women, what increases the frequency of sensitization to this substance with no occupational relationship, as could be seen in this study. The other allergens are related to the occupations most seen at the service. Thimerosal occupied second place among positive contact tests overall; however, it was not relevant to occupational activities. This high sensitization index is due to its frequent use in vaccines and, in the past, in products for the skin, eyes and ears.

The analysis of the occupational contact dermatitis data collected by the European Surveillance System on Contact Allergy (ESSCA), from 2002 to 2010, from 11 European countries, found a high risk of OCD for the following allergens of the European standard series: rubber chemicals (thiurams, mercapto compounds and IPPD), epoxy resin, methylchloroisothiazolinone/methylisothiazolinone, methyldibromo, glutaronitrile and formaldehyde. ${ }^{23}$

The polysensitization features among construction workers was also observed in this study. The most frequently identified allergens were: potassium dichromate, cobalt chloride, carba-mix, nickel sulfate, thiuram-mix, paraben-mix, epoxy resin and neomycin. Potassium dichromate is the main allergen in this occupation. Together with cobalt chloride it is more related to cement exposure. We attributed 7 cases positive for neomycin to the frequent use of this substance in the treatment of cutaneous lesions. Another problem commonly seen in construction workers is allergy to rubber additives present in PPEs. This is due to the use of these equipments over injured skin, facilitating cutaneous absorption of the allergen.

In an occupational dermatoses review article, Alchorne et al, commented that $50 \%$ of construction workers had ACD particularly due to work conditions and lack of PPEs. They considered as risks in these activities: cement metal contaminants (hexavalent chromium and cobalt), rubber vulcanizers in gloves (thiurams, carbamates, mercaptobenzothiazoles, paraphenylenediamine and hydroquinone) and woods. ${ }^{1}$

In the two prevalent occupations among women (housework and health professional) there was no prominent allergen. This was associated to the frequency of ICD in these occupations.

Common risk factors for OCD are: extensive exposure to potential allergens, to water, to solvents, to caustic materials and to microtraumas. Exposure to varied liquids and particularly to water have been associated to OCD due to humidity.,21,24 The occupations most frequently seen in this study (janitor/construction worker, cleaners, painter, health professionals, cook among others) expose the worker to humidity. Based on Danish guidelines for the diagnosis and treatment of hand eczema, Menné et al. considered as wetwork: moist hands for longer than 2 hours during one work day, washing of the hands more than 20 times per day and use of tight gloves for longer than 2 hours per work day. ${ }^{25}$

Regarding rubber gloves, even though the standard series includes many additives of this material, it was not always possible to detect allergy to these substances with patch testing. In 16 cases (39\%), the test with the standard series was negative but when performed with a fragment of the glove used by the patients, the results were positive, revealing allergy to other substances present in PPE that are not part of the standard series and need to be identified. It also emphasized the importance of performing the test, when possible, with objects used by the patients to confirm the presence of an allergen in the material.

Some eczematous dermatoses (hand atopic dermatitis, hand and/or feet tinea, ide reactions and palmar psoriasis) were mistaken for occupational contact dermatitis and referred for investigation at the service, contributing to an increase in the cases not related to work. On the other hand, there were also cases of contact dermatitis that were ruled out as occupational in origin after investigation.

An aspect of great relevance in this study refers to the fact that it is an epidemiological study conducted at a Service of Worker's Health in a country lacking this type of services. Thus, it contributes with information that can be used as parameters for new comparisons, besides providing support for other researches in Public Health.

The main limitation of this study is related to the fact that this was a specialized service with particular features, not allowing extrapolation of the results to the general population. The Brazilian standard series was an effective ancillary tool for the investigation of occupational contact dermatitis cases, supporting its routine use. This is due to the fact that it is composed of allergens found during occupational exposure and in the environment and allergens that are predominantly occupational. The lack of access to some substances not in the series also contributed to the occurrence of inconclusive cases.

\section{CONCLUSIONS}

The present study made possible the identification of the sociodemographic and clinical profile of the patients with occupational contact dermatitis seen at the OD service, as well as the occupational groups and main high-risk allergens for occupational contact dermatitis in this population. The data collected can contribute to the implementation of actions and policies in worker's health management, particularly in the organization of services and training of health professionals for the diagnosis and management of cases with occupational relevance. $\square$ 


\section{REFERENCES}

1. Alchorne AO, Alchorne MMA, Silva MM. Occupational dermatosis. An Bras Dermatol. 2010;85:137-45

2. Mathias CG. Occupational Dermatoses. In: Zenz C. Occupational Medicine. 3rd ed. St. Louis: Mosby Year Book; 1994. p. 9-13.

3. Dickel H, Bruckner T, Bernhard-Klimt C, Koch T, Scheidt R, Diepgen TL. Surveillance scheme for occupational skin dissease in the Saarland, FRG. First report from BKH-S. Contact Dermatitis. 2002:46:197-206.

4. Keegel T, Moyle M, Dharmage S, Frowen K, Nixon R. The epidemiology of occupational contact dermatitis (1990-2007): a systematic review. Int J Dermatol. 2009;48:571-8.

5. Diepgen TL. Occupational skin diseases. J Dtsch Dermatol Ges. 2012;10:297-313.

6. Ali AS. Dermatoses Ocupacionais. 2nd ed. São Paulo: Fundacentro/Fundunesp; 2010. 224 p.

7. Hernández E, Giesen L, Araya I. Análisis de las dermatitis de contacto ocupacionales en Chile. Piel. 2011;26:436-45.

8. Kucenic MJ, Belsito DV. Occupational allergic contact dermatitis is more prevalent than irritant contact dermatitis: a 5-year study. J Am Acad Dermatol. 2002:46:695-9.

9. Boonchai W, Thanomkitti K, Kasemsarn P. Occupational contact dermatitis in tertiary university hospital: a 5-year retrospective study. J Med Assoc Thai. 2014:97:1182-8

10. Bhatia R1, Sharma VK, Ramam M, Sethuraman G, Yadav CP. Clinical profile and quality of life of patients with occupational contact dermatitis from New Delhi, India. Contact Dermatitis. 2015;73:172-81.

11. Contact Dermatitis Brazilian Studying Group, Departamento Especializado de Alergia em Dermatologia da Sociedade Brasileira de Dermatologia. Multicentric study for the development of a standard Brazilian patch test series. An Bras Dermatol. 2000;75:147-56.

12. Brasil. Ministério da Saúde. Secretaria de Atenção à Saúde. Departamento de Ações Programáticas Estratégicas. Dermatoses ocupacionais. Brasilia: Editora do Ministério da Saúde, 2006. (Série A. Normas e Manuais Técnicos) (Saúde do Trabalhador; 9. Protocolos de Complexidade Diferenciada).
13. Hosmer DW, Lemeshow S. Applied Logistic Regression. New York: Wiley; 2000.

14. The data analysis for this paper was generated using SAS software. Copyright (c) 2016. SAS Institute Inc. SAS and all other SAS Institute Inc. product or service names are registered trademarks or trademarks of SAS Institute Inc., Cary, NC, USA.

15. Kanerva L, Estlander T, Jolanki R. Occupational skin disease in Finland. An analysis of 10 years of statistics from an occupational dermatology clinic. Int Arch Occup Environ Health. 1988:60:89-94.

16. Ibge.gov.br [Internet]. Instituto Brasileiro de Geografia e Estatística (IBGE). Conceitos [cited 2017 Jan 12]. Available from: http://www.ibge.gov.br/home/ estatistica/populacao/condicaodevida/indicadoresminimos/conceitos.shtm.

17. Clemmensen KK, Thomsen SF, Jemec GB, Agner T. Pattern of contact sensitization in patients with and without atopic dermatitis in a hospital-based clinical database. Contact Dermatitis. 2014;71:75-81.

18. Veien N. General aspects. In: Frosch PJ, Menné T, Lepoittevin J-P, editors. Contact Dermatitis. 4th ed. Springer; 2006. 201-254 p.

19. Carøe TK, Ebbehøj N, Agner T. A survey of exposures related to recognized occupational contact dermatitis in Denmark in 2010. Contact Dermatitis. 2014;70:56-62.

20. Lushniak BD. The epidemiology of occupational contact dermatitis. Dermatol Clin. 1995; 13:671-80.

21. Duarte I, Rotter A, Lazzarini R. Frequency of occupational contact dermatitis in an ambulatory of dermatologic allergy. An Bras Dermatol. 2010;85:455-9.

22. Reis RFD, Oliveira JI, Festino FS. Perfil clinico-ocupacional e resultados dos testes de contato dos pacientes atendidos em um ambulatório terciário de medicina do trabalho. Rev Bras Med Trab. 2012;10:95-9.

23. Pesonen M, Jolanki R, Larese Filon F, Wilkinson M, Kręcisz B, Kieć-Świerczyńska $M$, et al. Patch test results of the European baseline series among patients with occupational contact dermatitis across Europe-analyses of the European Surveillance System on Contact Allergy network, 2002-2010. Contact Dermatitis. 2015;72:154-63

24. Keegel TG, Nixon RL, LaMontagne AD. Exposure to wet work in working Australians. Contact Dermatitis. 2012;66:87-94.

25. Menné T, Johansen JD, Sommerlund M, Veien NK; Danish Contact Dermatitis Group. Hand eczema guidelines based on the Danish guidelines for the diagnosis and treatment of hand eczema. Contact Dermatitis. 2011:65:3-12.

\section{AUTHORS'CONTRIBUTIONS}

Statistical analysis; Approval of the final version of the manuscript; Conception and planning of the study; Elaboration and writing of the manuscript; Obtaining, analyzing and interpreting the data; Effective participation in research orientation; Intellectual participation in propaedeutic and/or therapeutic conduct of the cases studied; Critical review of the literature; Critical review of the manuscript
Ana Luiza Castro Fernandes Villarinho
D ORCID
0000-0002-4049-6114

Statistical analysis; Approval of the final version of the manuscript; Conception and planning of the study; Elaboration and writing of the manuscript; Obtaining, analyzing and interpreting the data; Effective participation in research orientation; Intellectual participation in propaedeutic and/or therapeutic conduct of the cases studied; Critical review of the literature; Critical review of the manuscript

Iuri da Costa Leite

(iD) ORCID

0000-0002-9136-8948

Statistical analysis; Approval of the final version of the manuscript; Conception and planning of the study; Elaboration and writing of the manuscript; Obtaining, analyzing and interpreting the data; Effective participation in research orientation; Intellectual participation in propaedeutic and/or therapeutic conduct of the cases studied; Critical review of the literature; Critical review of the manuscript

How to cite this article: Melo MGM, Villarinho ALCF, Leite IC. Sociodemographic and clinical profile of patients with occupational contact dermatitis seen at a work-related dermatology service, 2000 - 2014. An Bras Dermatol. 2019;94(2):147-56. 